\title{
Patient safety a matter of design
}

$\mathrm{A}$ $\mathrm{n}$ international group of health care systems has begun a yearlong project to gather and share data on how to design systems to improve patient safety.

Leading Health Systems Network (LHSN), a partnership between Qatar's World Innovation Summit for Health (WISH) and Imperial College London, launched the Safer Care Accelerator in March to share best practices and expedite improvement in patient safety. The network is a group of 16 health systems from around the world, including Vancouver Coastal Health and Quebec's Institut national d'excellence en santé et en services sociaux (INESSS), that share data and benchmark their performance against one another.

Deidre Thompson, a policy fellow at Imperial who works on the LHSN, says the network will spend the initial few months developing its Patient Safety Scorecard, which aims to determine what information health systems collect about adverse events and what they do with those data. The aim is to identify gaps, she says.

"Most health systems can't tell you what their top problem is - there's a real lack of ability to quantify problems with safety."

Once the scorecard is completed, the second half of the project will focus on developing and comparing solutions on one specific issue, such as pressure ulcers or hospital-acquired infections.

Patrick O'Connor, vice president of medicine, quality and safety at Vancouver Coastal Health, says the project is a good opportunity to learn new approaches to patient safety. "Adverse events are not uncommon in health care. We look at all sorts of areas where we can find best practices and what we might change to get there, and I think that's an interest shared by most of the members of the network."

As for what the Canadian partners might have to offer, O'Connor says the

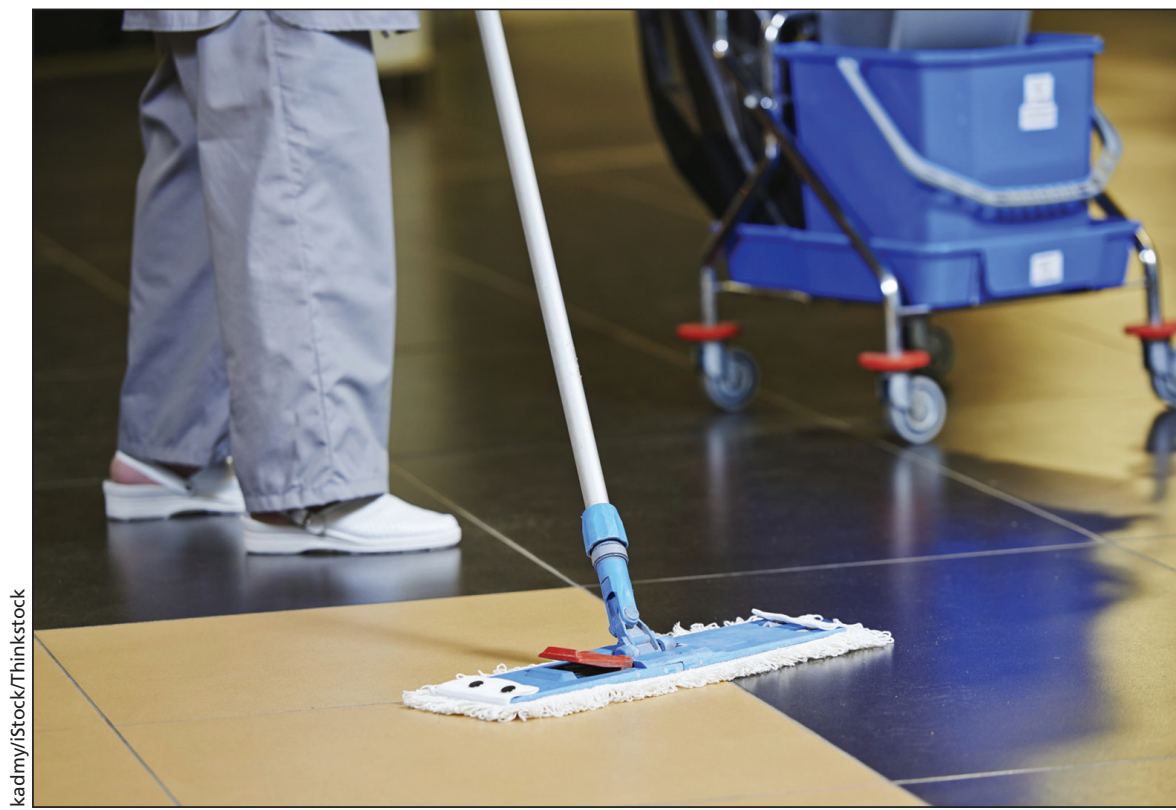

An international partnership of 16 health systems, including 2 in Canada, will develop and compare solutions on patient safety issues such as hospital-acquired infections.

network is particularly interested in the hospital harm indicator being developed by the Canadian Institute for Health Information, which will monitor patient safety data across Canada, and how it could be applied in other health systems. And he thinks the systems that Vancouver Coastal Health has put in place to combat Clostridium difficile infections - from managing antibiotic use to ensuring that mobile equipment is properly cleaned — will be of use to international partners.

Finding ways to improve patient safety is a major concern for hospitals and health systems around the world. The World Health Organization estimates that in developed countries as many as 1 in 10 patients are harmed while receiving care and $20 \%$ to $40 \%$ of health care spending is wasted because of poor-quality care.

Peter Pronovost, vice president for patient safety and quality at Johns Hopkins Medical Institute in Baltimore, Maryland, chaired a research forum for WISH that examined patient safety. He says there are three attitudes holding back progress on providing safer care: that harm is inevitable, that safety is based on the heroism of clinicians and that people are powerless to change the system.

Instead, Pronovost says the health care sector needs to engineer systems that make it harder for preventable harm to happen in the first place. "We need to start thinking like a systems engineer. Start at the end goal of no harm, and work backwards to how we can achieve it."

That kind of systems approach could have a profound impact on health care improvement for the next 50 to 100 years, says Pronovost. And it's exactly what the LHSN partners hope to achieve by sharing their experiences, says O'Connor. "Health care is a human business, and humans make mistakes," he says. "The question is: how can we avoid them? We're looking for systems that eliminate the opportunity for error." - Brian Owens, St. Stephen, NB

CMAJ 2015. DOI:10.1503/cmaj.109-5038 